\title{
The Influence of Platform Economy on Financial Function
}

\author{
Xiaoyan Zhang ${ }^{1 *}$ \\ ${ }^{1}$ Master of Commerce, The University of Sydney, Sydney, NSW2006, Australia \\ *Corresponding Author's Email:1045651489@qq.com
}

\begin{abstract}
Today, with the rapid development of Internet information technology, the platform economy (PE)model covers most areas of people's economic life, and has caused subversion and innovation to the business model and pattern of the traditional financial industry. PE plays a significant role in the development of Internet finance(IF), and the trend of platform is irreversible. The scale effect of PE is huge. It connects with a large number of middle and long tail users with almost zero marginal cost, which fundamentally endows the IF industry with broad market potential, imagination and creativity. Platform is the basis of IF business model. This paper mainly studies IF from the perspective of PE, and analyzes the impact of PE on financial function(FF).This paper analyzes the influence of PE on FF, studies the function of financial system, and analyzes the influence of PE on IF from two aspects of platform industry chain and business reconstruction. Based on the perspective of $\mathrm{PE}$, this paper analyzes the impact of platform industry chain and business restructuring on IF, and selects two aspects of business restructuring, insurance business and credit reference. The results show that from 2015 to 2019 , the Internet insurance business has more than quadrupled, accounting for $31.35 \%$ of the whole industry in 2015 and $72.46 \%$ in 2019. The Internet insurance business has developed steadily under the promotion of PE.
\end{abstract}

Keywords: Platform Economy, Financial Function, Online Finance, Financial Model

\section{INTRODUCTION}

The development of IF is a financial innovation based on PE. It is a product of the integration of platform scale effect, network externality effect, zero marginal cost effect and Internet technology. Technology drives change and platform construction scenarios [1-2]. Based on the scale effect and extremely low marginal cost of $\mathrm{PE}, \mathrm{IF}$ has achieved explosive growth, but also exposed some risks and problems. It is necessary to study and analyze IF combined with the effect of PE [3-4]. The large-scale development of PE is inseparable from the maturity of Internet economy and the progress of science and technology. Especially in China, the entry of e-commerce platform into the financial field is far more rapid and powerful than the Internet transformation of traditional financial industry [5-6]. The early development and maturity of e-commerce mode provides valuable reference for it, and then realizes the innovation of business format and the construction of scenarios. Traditional financial institutions almost give up the middle and long tail user market actively or passively, which also leaves potential reserves for the development of IF [7-8]. The research on IF from the perspective of PE is helpful to understand the importance of technology driving for business restructuring, improve the level of risk control, reasonably implement policy support, and promote the further development of China's Inclusive Finance and even move towards a broader blue ocean market, which will fundamentally improve China's investment and financing environment [9-10].

In the research of PE and FF mode, many scholars at home and abroad have studied it, and have made some research results. Ryazanova GN et al. pointed out that the characteristics of Internet financial platform effectively reduce the information cost, management cost, search cost and a series of marginal costs, comprehensively improve the efficiency of capital allocation and the quality of financial services, and on this basis derive a variety of financial innovation products to cope with the growing demand of customers and promote the improvement of the overall consumption capacity of society [11]. Manco $O$ pointed out that as a basic economic phenomenon, PE has existed for a long time. In the process of development, $\mathrm{PE}$ is subject to certain 
restrictions, showing different regional characteristics. According to this characteristic analysis, it can fully coordinate the "cross externality" factors, highlight the traditional restrictive elements, and develop and grow rapidly in different Internet platforms [12].

This paper mainly studies IF from the perspective of $\mathrm{PE}$, and analyzes the impact of PE on FF. This paper studies the functions of the financial system and finds out its six functions: clearing and settling payments, accumulating resources and dividing shares, transferring resources in time and space, risk management, providing information and dealing with incentive problems. This paper also analyzes the impact of PE on IF from two aspects of platform industry chain and business restructuring, and understands that IF takes user resources as the core to excavate and create value on the basis of PE. This article from the platform industry chain and business restructuring to understand its impact on the IF, and select the business restructuring of the insurance business and credit field of two aspects for specific analysis.

\section{THE INFLUENCE OF PE ON FF}

\subsection{Functions of Financial System}

(1) Responsible for the clearing and settlement of payments

Clearing refers to the processing of payment notice, that is, the determination and calculation of the responsibilities of all parties to the transaction. Settlement is the actual settlement of the responsibilities of all parties to the transaction. The reason why the financial system undertakes this function is considered to be due to the transaction cost. The transaction costs of the clearing and settlement process include: the cost of processing payment notices, the cost of financing or preserving collateral, commission of brokers, bid ask spread and various forms of taxation.

(2) Accumulation of resources and division of shares

With the development of economy, enterprises continue to expand their optimal scale, while the growth of family wealth is far behind the expansion of project scale. The function of the intermediary to accumulate resources and split shares is very important for enterprises. For families, investment through intermediaries can bring about three benefits at a lower cost: fully dispersed assets, guaranteed liquidity, access to enterprise information and supervision of entrepreneurs. In addition, the intermediary can also provide the claim that the market does not have, that is, the securities that do not meet the requirements of investors or are not understood by investors become the securities that meet the requirements of investors or are not information intensive.
(3) Transfer resources in time and space

Transferring resources across time and space involves borrowing, which has certain risks. Because a risk-free loan is equal to a risk-free loan plus a repayment guarantee, that is: risk-free loan = risk loan + repayment guarantee, on the other hand, we can get: risk loan = risk-free loan repayment guarantee. Therefore, issuing a risky loan is equivalent to issuing a risk-free loan and selling an insurance policy involving the borrower's default risk. Therefore, the function of financial institutions also includes default risk management, which includes risk assessment and solving adverse selection and moral hazard problems under asymmetric information. For the surplus of funds, the function of intermediary can not only make them obtain income, but also ensure the safety of funds; for the demanders of funds, the evaluation, guarantee and supervision of the intermediary can enhance their credit and make it easier to obtain funds at a lower cost.

(4) Risk management

There are no more than three means of risk management: asset diversification, hedging and insurance. In capital asset pricing model (CAPM), there are two options for investors to diversify assets: first, they can directly choose the appropriate positions of various risk securities and risk-free securities; second, there are two funds, one of which only includes risk-free securities, and the other includes all risk securities, Investors can choose two kinds of funds according to their preference and endowment. The two funds here can be understood as two financial intermediaries. The framework of CAPM is relatively simple. In fact, in reality, every investor may have his own unique utility function. According to CAPM model, the utility function is given:

$$
E r_{j}=r_{f}+\beta\left(E\left(r_{m}\right)-r_{f}\right)
$$

$r_{f}, \beta, E\left(r_{m}\right)$ is the correlation coefficient of risk-free rate of return, when the utility function of investors depends on different state variables, there will be two cases: first, if these state variables are related to the existing securities, the optimal portfolio of economic parties will change, and the separation theorem of two funds in CAPM will be invalid. If there are $m$ kinds of state variables, then in order to achieve the optimal asset dispersion through intermediary, we need to have $m+2$ funds. Because the reality is complex, the number of funds required is very large, which implicitly explains the complexity of the financial system. Second, if these state variables are not related to the existing securities, the optimal portfolio will not change, but the consumption saving decision will be affected. At this time, the intermediary is needed to produce some financial instruments to hedge the unique risks faced by 
economic parties, which is the hedging means in risk management.

\section{(5) Provide information}

The main theories of modern finance are originated from the core view of the French mathematician bashelier: securities prices follow random walk, so they are unpredictable. In order to make the price have the information function, it must require the existence of some kind of friction: first, the parties are bounded rational, they can't grasp all the information about the future, or even if they do, they don't have the complete knowledge to deal with the information; second, the speed of the market is not infinite, there is enough arbitrage time before reaching the equilibrium price.

(6) Dealing with incentives

The incentive problem comes from adverse selection and moral hazard caused by information asymmetry. The incentive problem has both similarities and differences with other obstacles. The similarities lie in that, like transaction cost and communication cost, the incentive problem can also be alleviated through technological progress and contract design; the difference lies in: the incentive problem is a more basic problem faced by the financial system. Even if the transaction cost and communication cost are completely disappeared due to the development of technology, the incentive problem will still exist and bring great cost to the operation of the financial system and society. It's as if the technology of making locks can reduce theft, but never eradicate it. For companies, on the one hand, asymmetric information will lead to lemon market problems when companies need external financing, which makes the positive NPV projects can not get enough funds and lead to underinvestment; on the other hand, asymmetric information will lead to the moral hazard of the managers in the company, so that the company's funds are invested in the projects that are good for the managers but have negative NPV, which leads to the phenomenon of over investment. NPV should be maximized, that is:

$$
N P V=C_{0}+E C_{1} /\left(1+E r_{j}\right)
$$

Among them, $C_{0}$ is the cost of investment, $E C_{1}$ is the expected cash flow, accepting positive NPV and rejecting negative NPV can maximize the value of the enterprise.

\subsection{Impact of PE on IF}

(1) Analysis of platform industry chain

IF is a platform for the adaptation of funds and assets. It relies on Internet technology and takes online financial products as the media to complete the financing; through technical means to achieve the analysis of user information resources and demand mining, solve the pricing problem; through the payment account to achieve payment, consumption, trading functions, improve the mobile financial chain, so as to form a platform, information, account of the whole industry chain. Platform users all have an account. The account has the function of monetary support, which is the need of platform and product transaction and the carrier of payment. Its commercial value lies in the transaction, exchange and payment. In addition, the payment interface is the key to the flow import, which is connected with the front-end big data analysis to achieve closed-loop, and has been extended in many fields such as credit reference, consumer finance, etc. At present, the Internet platform is divided into three categories, namely, the traditional platform of Internet, the Internet financial innovation platform and the IF + industry interconnection platform. In general, the functional modules of the platform can be simply abstracted into three parts, namely capital side + asset side + risk management.

\section{(2) Business Restructuring}

With the rapid development of Internet financial platform, its influence has brought great challenges to the traditional financial field. The traditional financial business is under serious pressure, and actively seeking business restructuring is mainly reflected in five aspects.

First, loan business. Business disintermediation, taking $\mathrm{P} 2 \mathrm{P}$ as a typical example, the investment and financing parties dock on the platform. The platform not only collects and feeds back relevant information, but also realizes disintermediation business matching, and the profit is transformed from interest margin to service related income. Risk control has expanded from the control of simple collateral to the measurement and decentralization based on big data. In addition, P2P lending can serve the long tail population based on zero marginal cost, which helps to realize the financing of small and micro enterprises and individuals.

Second, equity investment. The business mode of equity crowd financing is based on Internet plus finance, a new form of innovation. Its connotation is not focused on financial innovation itself, but subversive challenges to traditional financial sectors and business forms. The flat Internet architecture of the crowdfunding platform effectively reduces the degree of information asymmetry between the participants. The decentralized improvement of analysts can obtain views from the user's original content, and use the leading investment and follow-up investment mode to achieve small amount of diversified investment.

Third, insurance business. The marketing channels of insurance business have changed from individual promotion and banking channels to Internet sales, some businesses have changed from manual claims to online claims, personalized business has been enhanced, and 
the income of fragmented small high-frequency consumer insurance products has increased.

Fourth, payment. Payment not only has the financial attribute, but also has the gene of information interaction, which is the core of the whole Internet financial problem. At present, the function of the third-party payment platform is relatively single, which is still dominated by payment, but it has made expansion attempts in other aspects. The mobile trend of payment demand is increasing, the occurrence of payment behavior is transferring to the Internet as a whole, the growth rate of PC terminal payment is slowing down, and the growth rate of mobile terminal payment is accelerating.

Fifth, the field of credit reference. Traditional credit data sources are relatively single, mainly by collecting bank credit data. The Internet platform has multiple sources of credit information: e-commerce, operators, social networks, credit, etc., with rich use scenarios. It can be combined with big data statistical methods to establish a credit database.

\section{RESEARCH AND ANALYSIS}

\subsection{Research Objects}

This paper mainly studies the impact of PE on FF. Based on the perspective of PE, this paper understands its impact on IF from the aspects of platform industry chain and business restructuring, and selects two aspects of insurance business and credit reference field in business restructuring for specific analysis, this paper analyzes the growth of IF and insurance under the PE and the proportion of financial credit reporting mode.

\subsection{Research Process Steps}

In order to study the growth of IF and insurance industry under the PE, this paper collects the data of all financial and insurance companies of IF from 2015 to 2019 through data mining technology, and integrates the proportion of IF and insurance in the whole insurance industry, so as to understand the rapid growth of Internet insurance industry under the development of PE. In addition, this paper also uses big data analysis technology to analyze the model types of financial credit reference field under the $\mathrm{PE}$, to understand the credit reference sources of China's financial credit reference field under the current IF, which is different from the single form of traditional financial credit reference mode.

\section{EXPERIMENTAL RESEARCH AND ANALYSIS ON THE IMPACT OF PE ON FF}

\subsection{Analysis of IF and Insurance Growth Under $P E$}

With the deepening of PE and the continuous development of IF, IF and insurance emerge spontaneously. Internet insurance refers to the insurance service platform serving the Internet and related industries. Through Internet thinking, insurance and financial products are modularized to form new insurance products. With the development of PE, the Internet insurance industry has achieved rapid growth, and the data results are shown in Table 1.

Table 1.Growth of IF and insurance under PE

\begin{tabular}{|c|c|c|c|c|c|}
\hline & 2015 & 2016 & 2017 & 2018 & 2019 \\
\hline Number of Internet insurance companies & 27 & 35 & 54 & 80 & 111 \\
\hline Proportion & 31.35 & 33.13 & 39.74 & 48.79 & 72.46 \\
\hline
\end{tabular}

As can be seen from Figure 1, from 2015 to 2019, the development of Internet insurance business has more than quadrupled, from $31.35 \%$ of the whole industry in
2015 to $72.46 \%$ in 2019. Internet insurance business has developed steadily under the promotion of PE. 


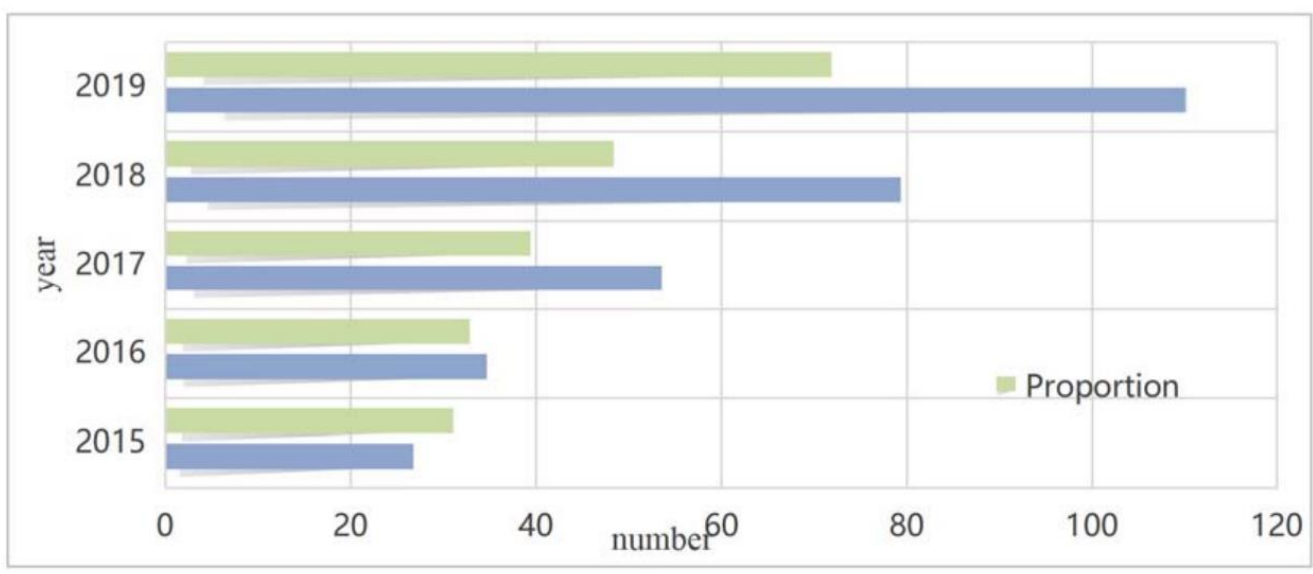

Figure 1. Growth of IF and insurance under PE

\subsection{Mode Analysis of Financial Credit Reference Field Under PE}

From the perspective of PE, the influence of FF also exists in the field of financial credit reference. At present, the field of Internet financial credit reference in China has just started, and its main credit evaluation fields are shown in Figure 2.

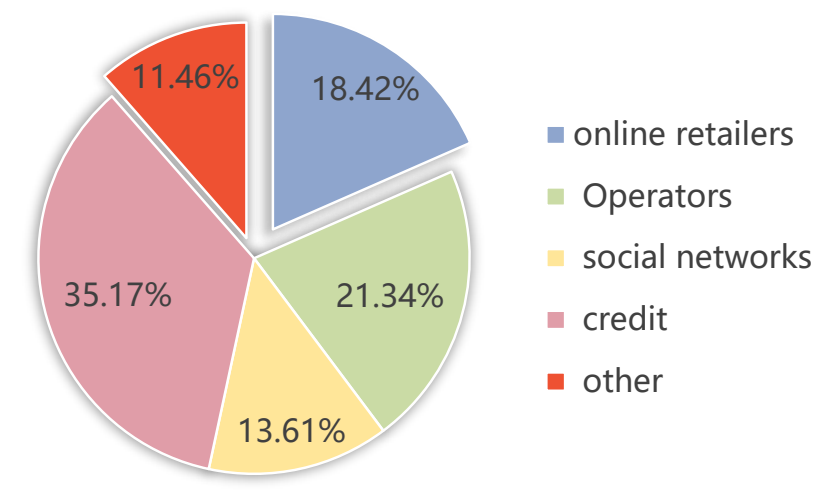

Figure 2. Analysis on the mode of financial credit reference under PE

As can be seen from Figure 2, the IF Based on the development of PE has no more single credit source than the traditional finance. Under the IF, credit account for $35.17 \%$, e-commerce account for $18.42 \%$, operator account for $21.34 \%$, social network account for $13.61 \%$, and other credit account for $11.46 \%$.

\section{CONCLUSIONS}

In recent years, China's Internet amount industry has experienced rapid growth, many excellent platforms began to contact Internet financial business, and high-quality platforms further integrate resources. This paper studies the impact of $\mathrm{PE}$ on FF from the perspective of $\mathrm{PE}$, but due to the numerous business modules of IF and the rapid development of financial technology, this paper has some limitations. In the future research, scientific analysis and more accurate data can be used to support the discussion, hoping to contribute to the influence between PE and FF.

\section{REFERENCES}

[1] Katz M L . Platform economics and antitrust enforcement: A little knowledge is a dangerous thing[J]. Journal of Economics \& Management Strategy, 2019, 28(1):138-152.

[2] Akbar Y H , Tracogna A. The sharing economy and the future of the hotel industry: Transaction cost theory and platform economics[J]. International Journal of Hospitality Management, 2018, 71:91-101.

[3] Zisopoulou K, Karalis S , Koulouri M E , et al. Recasting of the WEF Nexus as an actor with a new economic platform and management model[J]. Energy Policy, 2018, 119:123-139. 
[4] Uriin D , Lonar D . Shaping the future of Serbia's economy: The new growth model and related economic policy platform[J]. Ekonomika preduzeca, 2020, 68(1-2):1-21.

[5] Wang C L. Policy suggestions on developing platform economy in Jiangsu Province during the 13th Five Year Plan period [J]. Value engineering, 2016, 000 (001): 252-254.

[6] Mallick S , Matousek R , Zeremes N G T . Financial development and productive inefficiency: A robust conditional directional distance function approach $[\mathrm{J}]$. Economics Letters, 2016, 145(8):196-201.

[7] A C R S , B D D F , C E U W . Catch me if I fall: Cross-national differences in willingness to take financial risks as a function of social and state 'cushioning' $[\mathrm{J}]$. International Business Review, 2017, 26( 6):1023-1033.

[8] Qi Y. Research on the Relation between Financial Function and the Improvement of Industry Comparative Advantage from the Perspective of
Supply and Demand-Literature Review[J]. Finance, 2020, 10(2):61-67.

[9] Song H, Liu M . On the Influence of Platform Economy on Transformation and Upgrading of Chinese Traditional Manufacturing Industry - A Case Study of Red Collar Group[J]. IOP Conference Series: Materials Science and Engineering, 2020, 711(1):012023 (8pp).

[10] Mao J F, Lin X. The Influence of Business Model Innovation on the Transformation of Financial Function -- Enterprise Finance: From Value Accounting to Revenue Creation [J]. Journal of Shandong University of business and technology, 2018, 032 (002): 24-31.

[11] Ryazanova G N , Sazanova A A, Sazanova S L . The influence of the processes of digitalization of the economy on the activities of non-financial institutions[J]. Upravlenie, 2018, 6(2):52-56.

[12] Manco O , Botero O , Medina S . Risker: Platform Implementation of Complex System Model for Financial Risk Management in Energy Markets[J]. Procedia Computer Science, 2016, 8(3):1078-1083. 